\title{
The sensitivity of diphtheria bacilli to eight antibiotics
}

\author{
IRAJ ZAMIRI AND M. G. MCENTEGART \\ From the Department of Medical Microbiology, University of Sheffield
}

SYNOPSIS Antibiotics are of equal importance to antitoxin in the treatment of diphtheria, as an $\frac{\overrightarrow{\vec{\omega}}}{\vec{\omega}}$

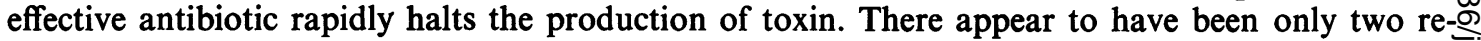
ports of the sensitivity of diphtheria bacilli to various antibiotics and these are based on thes examination of less than 60 strains. In this paper the sensitivity of 192 strains to eight representative antibiotics is reported.

Of the 192 strains examined, 151 (136 gravis, 12 mitis, three intermedius) were isolated in Iran. The remaining 41 were isolated in the United Kingdom. The latter strains included 40 identified as nontoxigenic mitis, and one $C$. ulcerans. The criteria used in the biotyping of these strains were those described by McLeod (1943). In differentiating those with less distinctive morphology into mitis or gravis strains, starch fermentation was taken as the deciding characteristic.

\section{Methods}

There are many methods available for the estimation of antibiotic sensitivity and after some preliminary trials we decided to adopt the agar dilution method recommended by Erricson and Sherris (1971).

The antibiotics examined were benzylpenicillin, ampicillin, oxytetracycline, erythromycin, cephaloridine, lincomycin, clindamycin, and neomycin, and the dilutions tested ranged from $3.2 \mu \mathrm{g} / \mathrm{ml}$ to 0.0125 $\mu \mathrm{g} / \mathrm{ml}$.

Test dilutions of the various antibiotics examined were incorporated in Oxoid DST agar. Broth cultures for the inoculation of these plates were prepared as follows.

Single colonies picked from blood agar were grown overnight on Loeffler slopes. A heavy inoculum was seeded from these slopes into $5 \%$ bovine serum broth, which after incubation for 18 hours at $32^{\circ}$ was diluted to give a colony count of approximately $10^{8} / \mathrm{ml}$.

A modified PHLS phage applicator (Lidwell, 1959) was used to place 24 test strains and the control (Staph. aureus) on the antibiotic-containing agar plate. An antibiotic-free agar plate acted as a final control to check the growth of the test organisms. Plates were incubated at $37^{\circ} \mathrm{C}$ and the results were read 24 hours later.

\section{Results}

The Table shows the range of the sensitivity of the organisms and their biotypes, and the Figure demonstrates the percentage of strains sensitive to the antibiotics at the dilutions stated. The non-toxigenion mitis strains showed a similar range of sensitivitieš and did not differ in this way from toxigenic strains $\stackrel{\triangle}{\varrho}$

\begin{tabular}{|c|c|c|c|}
\hline \multirow[t]{2}{*}{ Antibiotic $(\mu g / m l)$} & \multicolumn{3}{|c|}{ Biotypes of $C$. diphtheriae } \\
\hline & Gravis & Mitis & Intermediu \\
\hline $\begin{array}{l}\text { Benzylpenicillin } \\
\text { Ampicillin } \\
\text { Oxytetracycline } \\
\text { Erythromycin } \\
\text { Cephaloridine } \\
\text { Lincomycin } \\
\text { Clindamycin } \\
\text { Neomycin }\end{array}$ & $\begin{array}{l}0.025-0.4 \\
0.2-0.4 \\
0.4-1.6 \\
0.0125-0.05 \\
0.05-0.2 \\
0.1-0.4 \\
0.025-0.2 \\
0.025-0.4\end{array}$ & $\begin{array}{l}0.025-0.4 \\
0.05-0.8 \\
0.4-0.8 \\
0.0125-0.5 \\
0.05-0.4 \\
0 \cdot 1-0.8 \\
0.05-0.4 \\
0.025-0.2\end{array}$ & $\begin{array}{l}0.05-0 \cdot 1 \\
0.2-0.4 \\
0.4 \\
0.025 \\
0.05 \\
0.2 \\
0.5 \\
0 \cdot 1-0.2\end{array}$ \\
\hline Total no. of strains & 136 & $53^{1}$ & 3 \\
\hline
\end{tabular}

Table Antibiotic sensitivity of 192 strains of

C. diphtheriae according to their biotypes

${ }^{1}$ Including one strain of $C$. ulcerans.

These results confirm the previous findings that of the antibiotics used systemically, erythromycin is the most active. Clindamycin, the MIC and clinical use of which have not been reported so far, was more active than penicillin and might therefore be considered as an alternative in the treatment of the carrier of diphtheria bacilli, especially in those wh ${ }^{+}$ are sensitive to penicillin. Cephaloridine was as active as benzylpenicillin and twice as active as ampicillin? 


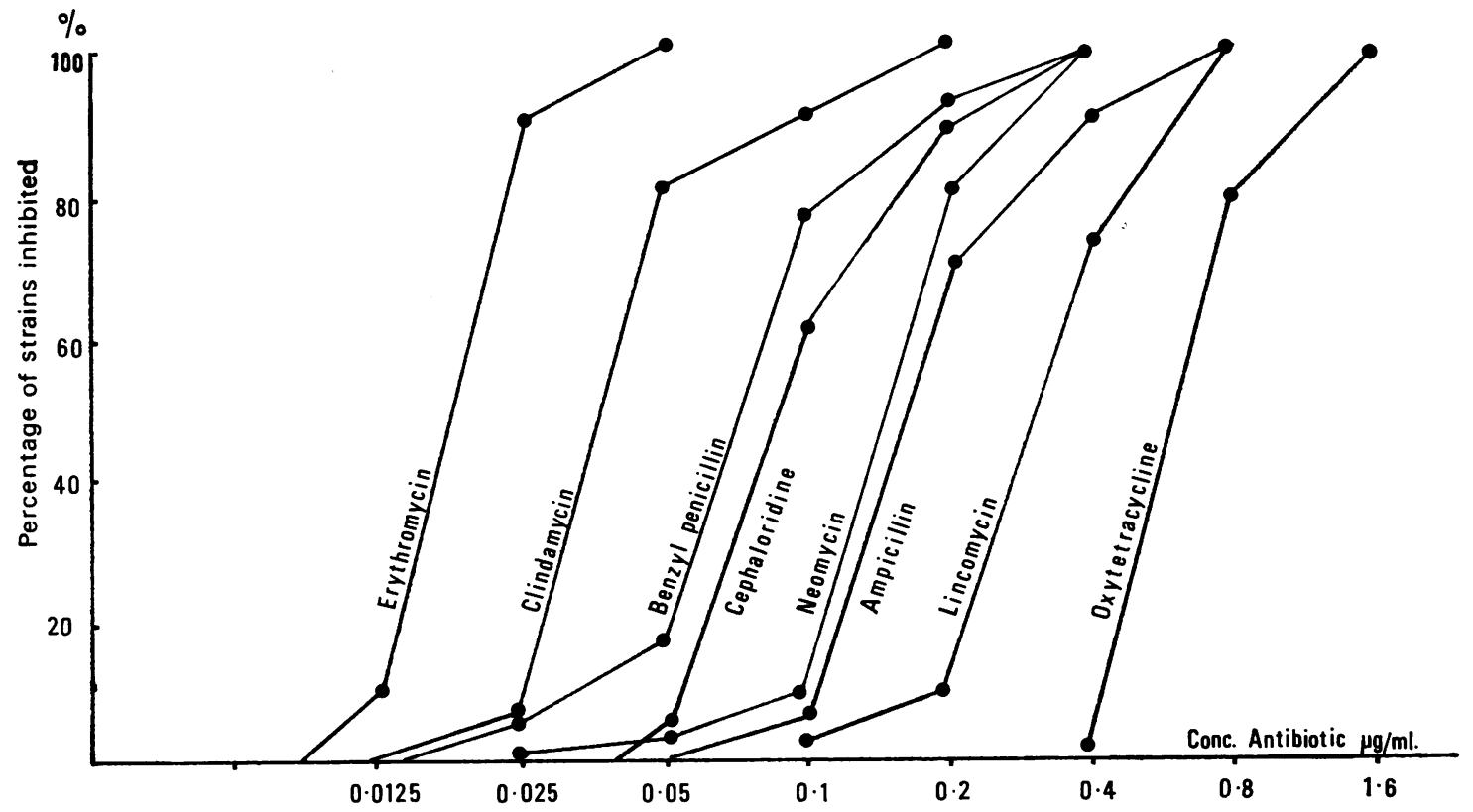

Fig. Percentage of 192 strains of C. diphtheriae sensitive to each dilution of eight antibiotics tested.

Oxytetracycline was the least active of the eight antibiotics studied. The organisms we tested were more sensitive to penicillin, ampicillin, lincomycin, and caphaloridine than those reported so far (Gordon, Yow, Clark, and Stephenson, 1971).

An effective antibiotic, eg, penicillin, not only destroys the diphtheria bacilli but rapidly prevents the production of further toxin (Barksdale, Garmise, and Rivera, 1961), whereas antitoxin neutralizes the circulating toxin but does not prevent its formation. We therefore suggest that in the treatment of diphtheria, antibiotic therapy should be considered equal in importance to antiserum and given with the same urgency.
We would like to thank the Wellcome Trust for supporting the original diphtheria research project to which this is related, and Upjohn Ltd for the supply of lincomycin and clindamycin.

\section{References}

Barksdale, L., Garmise, L., and Rivera, R. (1961). Toxinogeny in Corynebacterium diphtheriae. J. Bact., 81, 527-540.

Erricson, H. M., and Sherris, J. C. (1971). Antibiotic sensitivity testing: report of an international collaborative study. Acta path. microbiol. scand., Suppl., 217.

Gordon, R. C., Yow, M. D., Clark, D. J., and Stephenson, W. B. (1971). In vitro susceptibility of Corynebacterium diphtheriae to thirteen antibiotics. Appl. Microbiol., 21, 548-549.

Lidwell, O. M. (1959). Apparatus for phage-typing of Staphylococcus aureus. Mth. Bull. Minist. Hlth Lab. Serv., 18, 49-52.

McLeod, J. W. (1943). The types mitis, intermedius and gravis of Corynebacterium diphtheriae. Bact. Rev., 7, 1-41. 